\title{
Diagnosing and Teaching Students with Social Communication Disorder in Included Classrooms
}

\author{
Christopher F. Mulrine ${ }^{1} \&$ Betty Kollia ${ }^{2}$ \\ ${ }^{1}$ Dept. of Special Education, Professional Counseling, and Disability Studies, William Paterson University of NJ, \\ Wayne, New Jersey, USA \\ ${ }^{2}$ Dept. of Communication Disorders and Sciences, William Paterson University of NJ, Wayne, New Jersey, USA \\ Correspondence: Christopher F. Mulrine, Dept. of Special Education, and Counseling Services, William Paterson \\ University of NJ, Wayne, New Jersey, USA. E-mail: Mulrinec@wpunj.edu
}

Received: May 4, $2020 \quad$ Accepted: June 15, $2020 \quad$ Online Published: June 25, 2020

doi:10.5539/jel.v9n4p94 URL: https://doi.org/10.5539/jel.v9n4p94

\begin{abstract}
Autism Spectrum Disorder (ASD) was for many years considered to be one of five pervasive developmental disorders (PDD) as defined in the 4th edition of the Diagnostic Statistical Manual of Mental Disorders (DSM-IV-TR) published by the American Psychiatric Association (APA, 2000). These disorders included Autism, Rett Syndrome, Childhood Disintegrative Disorder, PDD-NOS (not otherwise specified), and Asperger's syndrome. The 2013, fifth revision of the manual (DSM-5) presented a modification in the diagnosis for Autism Spectrum Disorder. It is now being diagnosed as an inclusive disorder of a range of symptoms or autism related symptoms from mild to severe (APA, 2013). It has dropped four of the previous diagnoses and is now only one encompassing disability called Autism Spectrum Disorder. Using the new DSM-5 diagnostic criteria some students who were previously diagnosed as having Asperger's Syndrome do not fit the new Autism Spectrum Disorder criteria. These students might now be diagnosed with Social Communication Disorder (SCD). This diagnosis meets the symptoms presented by these individuals more appropriately. SCD describes the social difficulties and pragmatic language differences that impact comprehension, production, and awareness in conversation that are not caused by delayed cognition or other language delays.
\end{abstract}

Keywords: social communication disorder, special education teachers, speech and language pathologists, classroom treatment, autism spectrum disorder

\section{Rationale for Article}

In a systematic review of 25 articles that evaluated samples of DSM-IV-TR and DSM-5 criteria for diagnosis of ASD a majority of studies indicated between $50 \%$ and $75 \%$ of individuals maintained their ASD diagnosis with the greatest decreases among high-functioning populations with IQs over 70 and/or previous diagnoses of PDD-NOS or Asperger's disorder (Smith, Riechow, \& Volkmar, 2015). According to this study, those diagnosed with Asperger's disorder or PDD-NOS might not meet diagnostic criteria for a diagnosis of ASD under the new DSM-5 criteria. In a similar study only $57.1 \%$ met the new criteria. Of the participants who met the DSM-IV-TR criteria for a PDD (i.e., autistic disorder, Asperger's disorder, and PDD-NOS), only 57.1\% met the DSM-5 criteria, with the high-functioning individuals (i.e., Asperger's disorder and PDD-NOS) less likely to meet DSM-5 criteria than those with autistic disorder. Failure to satisfy all three criteria in the social-communication domain was the most common reason for exclusion (39\%; Young \& Rodi, 2013).

This diagnosis has many common features with Asperger's Syndrome (Tangay, 2011, p. 1142). These changes affect students who were previously diagnosed as Asperger's Syndrome and the special education, general education, and Speech and Language Pathologists/Therapists (SLPs) who worked with these students. Even though the diagnosis has changed, these students are still present in the classroom and teachers and Speech and Language Pathologists (SLPs) need to know how to best support these students in the educational environment. This article will discuss how Social Communication Disorder is diagnosed for students and the treatments and interventions used by special education teachers and speech and language pathologists.

\section{DSM-5 Criteria for Autism Spectrum Disorder and Social Communication Disorder}

Using the new DSM-5 criteria for diagnosing Autism Spectrum Disorder (ASD), the condition is now identified 
by two broad categories of symptoms: problems with social communication and the presence of "stereotyped" behaviors, such as walking in certain patterns or insisting on specific, restricted, or unusual routines or abnormal sensory reactivity. To be diagnosed with ASD, these symptoms must arise during early childhood (NIH, 2013). According to the American Speech and Hearing Association (ASHA) Social Communication Disorder is the synergistic emergence of social interaction, social cognition, pragmatics (verbal and nonverbal) and receptive and expressive language processing (ASHA, 2016). The American Psychological Association defines Social Communication Disorder as an impairment of language pragmatics and is diagnosed based on difficulty in the social uses of verbal and non-verbal communication (DSM-5, APA, 2013). One of the main differences between Autism Spectrum Disorder and Social Communication Disorder (SCD) is that children with ASD have difficulties with social communication and they exhibit repetitive, restricted, stereotyped, inflexible, ritualized, and/or disruptive behaviors (DSM-5, APA, 2013).

In the classroom, Social Communication Disorder (SCD) can affect social interactions through a reluctance to interact with other children and exclusion or rejection. These characteristics may involve a difficulty in cognitive functioning with the ability to organize ideas, difficulty recalling information and specific behavior challenges that might include high levels of frustration or frequent arguments (Kudar, 2003). These individuals may have trouble following social communication norms, using verbal and nonverbal signals, or altering language for different situations and audiences (Grohl, 2019). Students with Social Communication Disorder (SCD) will present as having persistent difficulties in the social use of verbal and non-verbal communication manifested in deficits using communication for social purposes, impairments of the ability to shift communication to match shifts in context or the needs of the listener, and difficulties understanding what is not explicitly stated, and non-literal language (Norbury, 2014; American Psychological Corporation, 2013).

\section{Assessment of Social Communication Disorder}

Social communication is the use of language in functional social contexts, and encompasses social interaction, social cognition, pragmatics (verbal and non-verbal), and expressive and receptive language processing (ASHA 2016). Assessment of deficits in the above areas initially begins with a communication screening and a hearing screening (to eliminate hearing loss as a potential influencing parameter). If necessary, the screening is followed by a comprehensive assessment to determine eligibility and whether services are needed. The potential comprehensive assessment typically involves administration of a standardized communication assessment battery. For instance, a multi-part assessment battery, the "Clinical Evaluation of Language Fundamentals-5" (CELF-5; developed by Wiig, Semel, and Secord in 2013), is used to assess, diagnose, and monitor changes in language and communication skills in young people aged from 5 years to 21 years, 11 months.

The CELF- 5 is comprised of 16 sub-tests, specific to different developmental stages, which are grouped to create a core language and additional language indices of linguistic performance (receptive, expressive, content, structure, and memory), and provides a comprehensive measure of verbal and non-verbal communication abilities (Coret \& McCrimmon, 2015). The test includes a pragmatics profile on which the examiner scores the student with input from caregivers and teachers and provides a list of communication intentions the student may demonstrate in social and classroom settings. The pragmatics skills that are rated include greetings, participation, turn-taking behaviors, body-language, topic maintenance, non-literal language, use of communication strategies, and information exchange. There are two forms; one for children 5-8 years and one for children 9-21 years. The students' skills or difficulties provide the baseline for intervention and progress monitoring during treatment. Consideration of cultural influences is cautioned as they may affect performance (Wiig, Semel, \& Secord, 2013).

Other assessment batteries being used are the Comprehensive Assessment of Spoken Language (CASL-2; Carrow-Woolfolk, 2017), that includes 14 stand-alone subtests, and allows evaluation of more complex skills, such as supralinguistics (comprehension and production of meaning which needs to be inferred, figurative language, double meaning, etc.), and pragmatics (appropriate language usage in various contexts and social situations). Similarly, the Oral and Written Language Scales II (OWLS-II; Carrow-Woolfolk, 2011) will measure receptive and expressive language skills. It includes four additional rating scales that assess four linguistic structures (lexical/semantic, syntactic, supralinguistic, and pragmatic). This test is used for persons aged 3.0-21.11 years. The Test of Language Development Intermediate 4th Edition (Hammill \& Newcomer, 2008), and the Pragmatic Language Observation Scale (Newcomer \& Hammill, 2009) may also be used.

The results of these tests are used by SLPs, special education and general education teachers, school psychologists, and other professionals to determine the presence of a communication delay/disorder or related disability and to establish a student's eligibility for special education and/or speech/language services and guide the selection of appropriate academic and treatment interventions. 


\section{Social Communication Disorder in the Classroom}

It is important for teachers to understand how SCD presents itself in the classroom since they may be the first to notice a student struggling with social communication competence and may need to initiate intervention strategies. According to Paul and Murray (2015), authors on Autism Speaks ${ }^{\circledR}$, a child with SCD is diagnosed based on difficulties with both verbal and non-verbal social communication skills. In the classroom, SCD may appear as deficiencies in verbal skills that may involve greetings, requests, information exchange, commenting and taking turns appropriately in conversation, talking appropriately in various situations, keeping on topic, modulating speech and intonation correctly. Non-verbal social deficiencies may appear as not understanding relevant gestures, body language, facial expression, eye contact, appropriate turn-taking in play, or physical proximity. These students may misunderstand social cues, avoid coming to school, show poor judgment, or have difficulty with tests (Conti-Ramsden \& Botting, 2004). Teachers and SLPs may notice a child who is having difficulties in adapting his or her communication in accordance with the context (e.g., group work with classmates vs. responding to teacher questions), difficulties following conversational conventions (e.g., appropriate turn-taking), confusion with ambiguity, metaphors, and inferences, as well as proper utilization of contextual cues (Grohol, 2019). These problems should be considered red flags that may warrant further assessment.

It is important to note that, since language impairment in school-age children may further impact social relations with peers, compared to typically developing peers (Timler, 2008a), language ability should be carefully assessed. In an effort to facilitate early identification of a possible SCD, the American Speech and Hearing Association (2017a, Appendix A) provides charts with the components of social communication, namely, social interaction, cognition, and pragmatics, and these charts can guide referral initiatives by teachers to help with screening and assessment. In addition, ASHA (2017b; Appendix B) avails tables with the milestones for social communication at different stages of the child's development from birth to adult. As an example, by 12 months of age an infant smiles back at his/her caregiver and follows his/her gaze, vocalizes to get attention, and participates in vocal turn-taking. These skills continue to develop, so that by 24 months of age, the child now has acquired and uses one and two-word combinations (not just vocalizations) to get attention from her caregiver, request and communicate; she uses personal and possessive pronouns (I, me, you, my, mine) and participates in verbal turn-taking; maintains a simple topic; and uses appropriate prosody at syntactic junctures. By age 4 years, the typical child has an evolved social language, replete with conversational repairs and jokes (see Appendices A and B).

\section{Accommodations and Interventions for Social Communication Disorder}

According to Friend and Bursuck (2012), classroom accommodations for students with communication disorders involve creating an atmosphere of acceptance, encouraging listening and teaching listening skills, using modeling to expand students' language and providing meaningful contexts for speech and language practice. Additionally, they recommend creating an atmosphere of acceptance, where a student does not worry or feel threatened about making a mistake in communication attempts. Teaching listening skills involves stressing words or inflection patterns that are important for the listener so as to discern the message (Friend \& Bursuck, 2012). Further, these authors make a case for modeling language usage, wherein a person expands on the students' expressive language skills by adding relevant information to their sentences. Other accommodations include providing situations for the student to practice their new communication skills in a variety of academic and social contexts (Friend \& Bursuck, 2012).

Treatment interventions for students with SCD should begin with a review of the strategies used for the previous Asperger's Syndrome diagnosis. These strategies addressed social interaction issues with peers, teachers, and others. These classroom interventions stressed teaching social behaviors, language skills, and nonverbal communication skills (Weedn et al., 2010). Successful classroom teaching strategies discussed pairing students with similar interests, avoidance of large groups and through reducing noise and talking in the classroom (Smith-Myles, 2016). These strategies also stressed that teachers should be patient and encourage participation in classroom activities, speak with students as they would with any other student and not interrupt or complete their thoughts for them (Torreno, 2020).

Treatment and interventions used by Speech Language Pathologists to address SCD have a primary focus on providing functional strategies for the children to apply in social contexts. The World Health Organization (WHO, 2001) developed the International Classification of Functioning, Disability, and Health (ICF), for health and health-related conditions as a framework to facilitate interprofessional practice (IPP) and person-centered care. This means that treatment goals ought to be identified by the person, in collaboration with the family and related professionals, so as to allow the person's participation in meaningful life activities and assumption of meaningful roles in everyday life. Person-centered functional goals maximize intervention outcomes and result in functional 
progress important to the child and/or his family.

Environmental interventions in schools usually involve teachers and peers and promote the child's engagement in natural social communications activities (Timler, 2008b). Interventions may be provided via a variety of modalities, including current technologies (computers, videos, etc.) as well as augmentative and alternative communication (AAC; this is the use of objects to enable communication ranging from speech-generating devices to communication books, and communication techniques such manual signs, gestures etc.; ASHA, 2016). Targeted interventions should be curriculum-based, so as to promote cooperative learning and optimize the functionality of treatment.

\section{Specific Classroom Interventions to Enhance Social Competence}

Specific classroom interventions used for improving social skills mentioned in the literature include using comic strip conversations, Score Skills Strategies, the Social Communication Intervention Project, Social Stories, Social Scripts and Social Skills groups. Comic strip conversations are conversations between two or more people illustrated by simple drawings in a comic strip format. The drawings illustrate what people are saying and doing and what they might be thinking. The process of creating the comic strip slows the conversation down, allowing more time for an individual to understand the information being exchanged. Comic Strip Conversations can be used for conflict resolution, problem solving, communicating feelings and perspectives, and reflecting on something that happened (Gray, 1994). Another program designed to augment children's social abilities is called "Score Skills Strategy," was developed by Vernon, Schumaker, and Deshler in 1996 and targets the social skills necessary to share ideas with others, offer encouragement help to others, compliment other people, recommend changes in a nice way, and lastly exercise self-control. A third program discussed in the literature is called the "Social Communication Intervention Project (SCIP)" which is a speech and language therapy for school-age children with pragmatic and social communication needs. SCIP intervention focuses on social understanding and social interpretation (e.g., understanding social context cues and emotional cues), pragmatics (e.g., managing conversation, improving turn-taking), and language processing (e.g., improving narrative construction and understanding of nonliteral language (Adams et al., 2012). "Social Stories" ${ }^{\mathrm{TM}}$ " and video modeling are also effective strategies for teaching greeting responses to students with ASD, but generalization may be a problem (Kagohqra, 2012). The "Social Stories ${ }^{\mathrm{TM}}$ " program was structured to allow children with ASD to learn and practice socially suitable behaviors through various brief scenarios. These social stories aim to enhance children's understanding of acceptable ways to interact with others. The program has been successfully used to train correct social responsivity to children with other social difficulties (Gray, White, \& McAndrew, 2002). Another method, "Social Scripts" prompts children on the appropriate language to use in social exchanges. These visual and/or verbal prompts are scripted for consistency of instruction, and, as children use them increasingly on their own, they are gradually removed (Nelson, 1978). While typically developing children often learn implicitly, children with SCD benefit from direct instruction. The "Social Skills Groups" training paradigm involves explicit training, role playing of various types of social interactions, and feedback on appropriateness of interactions with peers. This is accomplished by a teacher or other professional facilitating a group of persons with SCD and can be adapted for various ages (Nelson, 1978; additional recommendations for educators and parents are presented in Appendix C).

\section{Conclusion}

In this article we addressed diagnosing and treating students with Social Communication Disorder in included classrooms. We discussed diagnostic criteria and steps for its assessment, the general therapeutics used by the speech language pathologists in addition to specific classroom interventions for teachers. It is important that school professionals be cognizant of the symptomatology and strategies needed for these students' social communication competence. These interventions can enrich the child's classroom experiences and be carried over to the child's home-life through the effective collaborative efforts between their teachers, SLPs, and family members.

\section{Acknowledgments}

The authors, Christopher F. Mulrine and Betty Kollia, guarantee that this manuscript is an original work and has not been previously published and is not being considered in whole or in part by another publisher.

\section{References}

Adams, C., Lockton, E., Freed, J., Gaile, J., Earl, G., McBean, K., ... Law, J. (2012). The Social Communication Intervention Project: A randomized controlled trial of the effectiveness of speech and language therapy for school-age children who have pragmatic and social communication problems with or without autism spectrum disorder. International Journal of Language \& Communication Disorders, 47, 233-244. 
https://doi.org/10.1111/j.1460-6984.2011.00146.x

American Psychiatric Association. (2000). Diagnostic and statistical manual of mental disorders IV (4th ed.). Washington, DC: Author.

American Psychiatric Association. (2013). Diagnostic and Statistical Manual of Mental Disorders: Diagnostic and Statistical Manual of Mental Disorders (5th ed.). Arlington, VA: American Psychiatric Association. https://doi.org/10.1176/appi.books.9780890425596

American Speech Language Hearing Association. (2016). Social Communication Disorder. Retrieved October, 2019 ,

from

https://www.asha.org/Practice-Portal/Clinical-Topics/Social-Communication-Disorders-in-School-Age-Chil dren/

American Speech Language Hearing Association. (2017a). Components of Social Communication. Retrieved from

https://www.asha.org/uploadedFiles/ASHA/Practice_Portal/Clinical_Topics/Social_Communication_Disor ders_in_School-Age_Children/Components-of-Social-Communication.pdf

American Speech Language Hearing Association. (2017b). Social Communication Benchmarks. Retrieved from https://www.asha.org/uploadedFiles/ASHA/Practice_Portal/Clinical_Topics/Social_Communication_Disor ders_in_School-Age_Children/Social-Communication-Benchmarks.pdf. Developmental Tables

Carrow-Woolfolk, E. (2011). Oral and Written Language Scales II (2nd ed., OWLS-2). Torrance, CA: Western Psychological Services.

Carrow-Woolfolk, E. (2017). Comprehensive Assessment of Spoken Language (2nd ed., CASL-2). Torrance, CA: Western Psychological Services.

Conti-Ramsden, G., \& Botting, N. (2004). Social Difficulties and Victimization in Children with SLI at 11 Years of Age. Journal of Speech, Language, and Hearing Research, 47(1), 145-161. https://doi.org/10.1044/1092-4388(2004/013)

Coret, M. C., \& McCrimmon, A. W. (2015). Test Review: Wiig, E. H., Semel, E., \& Secord, W. A. (2013). Clinical Evaluation of Language Fundamentals-Fifth Edition (CELF-5). Journal of Psychoeducational Assessment, 33(5), 495-500. https://doi.org/10.1177/0734282914557616

Davide-Rivera, J. (2015). DSM-5: New Diagnostic Criteria for Autism Spectrum Disorder (ASD). Autism Answers, Criteria and Diagnosis. Retrieved from http://aspiewriter.com/2015/08/dsm-v-new-diagnostic-criteria-for-autism-spectrum-disorder-asd.html

Frauwirth, S., Hamaguchi, P., \& Ross-Swain, D. (2016). Social Communication Disorders: Assessment of the Elementary School Child. ASHA Convention. Retrieved October 2019, from https://www.academictherapy.com/pdfs/ASHA_RESCA-E_presentation.pdf

Friend, M., \& Bursuck, W. D. (2012). Including Students with Special Needs: A Practical Guide for Classroom Teachers (6th ed.). Boston: Allyn \& Bacon, Pearson.

Gray, C. (1994). Comic strip conversations: Illustrated interactions that teach conversation skills to students with autism and related disorders. Arlington, TX: Future Horizons.

Gray, C., White, A. L., \& McAndrew, S. (2002). My social stories book. London, United Kingdom: Jessica Kingsley Publishers. $\quad$ Retrieved 2019, from https://www.asha.org/PRPSpecificTopic.aspx?folderid=8589934980\&section=Treatment

Grohol, J. (2019). Social (Pragmatic) Communication Disorder. Psych Central. Retrieved October, 2019, from https://psychcentral.com/disorders/social-pragmatic-communication-disorder/

Hammill, D. D., \& Newcomer, P. L. (2008). Test of language development-Intermediate (4th ed.). Austin, TX: PRO-ED.

Inglebret, E., Jones, C., \& Pavel, D. M. (2008). Integrating American Indian/Alaska Native culture into shared storybook intervention. Language, Speech, and Hearing Services in Schools, 39, 521-527. https://doi.org/10.1044/0161-1461(2008/07-0051)

Kagohara, D. et al. (2012). Teaching Two Students with Asperger Syndrome to Greet Adults Using Social StoriesTM and Video Modeling. Journal of Developmental and Physical Disabilities, 25(2), 241-251. https://doi.org/10.1007/s10882-012-9300-6 
Kuder, S. (2003). Teaching students with language and communication difficulties (2nd ed.). Pearson.

National Institutes of Health. (2013). Autism Spectrum Disorder: Uncovering Clues to a Complicated Condition. NIH News in Health, September 2013: A monthly newsletter from the National Institutes of Health, part of the U.S. Department of Health and Human Services. Retrieved October, 2019, from https://newsinhealth.nih.gov/2013/09/autism-spectrum-disorder

Nelson, K. (1978). How children represent knowledge of their world in and out of language: A preliminary report. In R. S. Siegler (Ed.), Children's thinking: What develops? (pp. 255-273). Mahwah, NJ: Erlbaum.

Newcomer, P. L., \& Hammill, D. D. (2009). Pragmatic language observation scale. Austin, TX: PRO-ED.

Norbury, C, F. (2014). Practitioner Review: Social (pragmatic) communication disorder conceptualization, evidence and clinical implications. The Journal of Child Psychiatry and Psychology, 55(3), 204-216. https://doi.org/10.1111/jcpp.12154

Paul, D., \& Murray, D. (2015). What is Social Communication Disorder? How is it Treated? Autism Speaks®. Retrieved Nov., 2019, from https://www.autismspeaks.org/expert-opinion/what-social-communication-disorder-how-it-treated

Rossana, S. (2020). Resources for autism and other developmental needs. Sped Advisor. Word Press.com. Retrieved February, 2020, from https://spedadvisor.com/about/

Smith, I., Reichow, B., \& Volkmar, R. (2015). The Effects of DSM-5 Criteria on Number of Individuals Diagnosed with Autism Spectrum Disorder: A Systematic Review. Journal of Autism and Developmental Disorders, 45, 2541-2552. https://doi.org/10.1007/s10803-015-2423-8

Smith-Myles, B., Hagen, K., Holverstott, J., Hubbard, A., Adreon, D., \& Trautman, M. (2016). Life Journey Through Autism: An Educator's Guide to Asperger Syndrome. Danya International Incorporated. Silver Spring, MD.

Tanguy, P. E. (2011). Autism in DSM-5. American Journal of Psychiatry, 168(11), 1142-1144. https://doi.org/10.1176/appi.ajp.2011.11071024

Timler, G. R. (2008a). Social knowledge in children with language impairments: examination of strategies, predicted consequences, and goals in peer conflict situations. Clinical Linguistics \& Phonetics, 22(9), 741-763. https://doi.org/10.1080/02699200802212470

Timler, G. (2008b, November). Social communication: A framework for assessment and intervention. The ASHA Leader, 13, 10-13. https://doi.org/10.1044/leader.FTR1.13152008.10

Torreno, S. (2020). Teaching students with communication disorders. Special education information for teachers and parents. BrightHub Education. Retrieved February, 2020, from https://www.brighthubeducation.com/special-ed-speech-disorders/113025-strategies-used-to-teach-students -with-speech-impairments/

Vernon, D. S., Schumaker, J. B., \& Deshler, D. D. (1996). The SCORE skills: Social skills for cooperative groups. Lawrence, KS: Edge Enterprises.

Weedn, A., \& Wofford, D. (2010). Teaching Students with Asperger's Syndrome: A Review of the Disorder and Suggested Strategies for Teachers. ProQuest Dissertations Publishing, Web.

Wiig, E. H., Semel, E., \& Secord, W. A. (2013). Clinical Evaluation of Language Fundamentals (5th ed.). San Antonio, TX: Pearson Clinical Inc.

World Health Organization. (2001). International Classification of Functioning, Disability and Health. ICF. Geneva: World Health Organization Publishing.

Young, R., \& Rodi, M. (2014). Redefining Autism Spectrum Disorder Using DSM-5: The Implications of the Proposed DSM-5 Criteria for Autism Spectrum Disorders. Journal of Autism and Developmental Disorders, 44, 758-765. https://doi.org/10.1007/s10803-013-1927-3

\section{Appendix A}

American Speech Language Hearing Association (2017a). Components of Social Communication. https://www.asha.org/uploadedFiles/ASHA/Practice_Portal/Clinical_Topics/Social_Communication_Disorders_ in_School-Age_Children/Components-of-Social-Communication.pdf 


\section{Appendix B}

American Speech Language Hearing Association (2017b). Social Communication Benchmarks. https://www.asha.org/uploadedFiles/ASHA/Practice_Portal/Clinical_Topics/Social_Communication_Disorders_ in_School-Age_Children/Social-Communication-Benchmarks.pdf. Developmental Tables

\section{Appendix C}

\section{Pragmatic Language Facilitation Tips}

There are several ways parents and teachers can help children use language appropriately in social situations. Social language use is known as "pragmatics." Some general suggestions are provided to help children develop skills in three major pragmatic areas. Although many of these suggestions are geared primarily for preschool children, they are modifiable for use with other children as well. The information below is adapted from the American Speech Language and Hearing Association's website that has a plethora of information on topics pertaining to Social Communication (https://www.asha.org/public/speech/development/Social-Communication/)

\section{Functional Language Use}

Help children use language differentially depending on their communicative purpose:

\section{Desired language function}

Comment

Request

Question

\section{Prompt for the child}

"What did you say/do then?"

"Tell me how..."

"Tell your classmate that you would like..."

"What would you like?"

"Ask me "what is...' ..."

Respond to a child's intended message rather than correcting the pronunciation or grammar, but provide an appropriate model in your own speech. For example, if a child says, "That's how it doesn't go," respond, "You're right. That's not how it goes."

Take advantage of naturally occurring interactions to increase use of different language functions. For example, practice greetings at the beginning of a day; have children ask peers what they want to eat for snacks; have children request necessary materials to complete an art project.

\section{Adaptive Language Use}

Practice different types of conversations that might occur with different people in different situations. For instance, try a new situation (or practice with a usual one) where the child gains experience saying the same story to different listeners. So, a child might be asked to tell the story of a movie to a younger child and to an adult. If the child's narrations are the same for each listener, model different language patterns for an adult and a child listener.

Nurture the child's usage of effective persuasion. Ask children what they would say, for example, to convince their parents to let them do something. Train and try various ways for children to convey what they want, for instance:

Polite ("Please, may I have a cupcake?") vs. impolite ("Give me the cupcake.")

Indirect ("The book smells dusty.") vs. direct ("Throw this book away.")

Explain why some requests would be more persuasive then others.

Conversational and Narrative Abilities

Start by discussing the child's subject of conversation. Add related information. This can further help a child say more about a particular topic.

- Give key words, pictures, or other visual prompts to guide the child in providing a story in the right sequence.

- Help the child to recast an unclear phrase by inquiring "Did you mean ...?"

- Explain how information is communicated in nonverbal signs. For instance, discuss how confusing it 
is when a person's facial expression does not align with the emotion that is narrated, like smiling while telling a sad story.

\section{Copyrights}

Copyright for this article is retained by the author, with first publication rights granted to the journal.

This is an open-access article distributed under the terms and conditions of the Creative Commons Attribution license (http://creativecommons.org/licenses/by/4.0/). 